\title{
Ácido tricloroacético como tratamiento para hiperplasia epitelial multifocal
}

\section{Trichloroacetic acid as a treatment for multifocal epithelial hyperplasia}

\author{
Clara Alicia Muñoz-Trejo,* Dafne Verónica Rosado-Rosado,* Martha Gabriela Chuc-Gamboa,* \\ Fernando Javier Aguilar-Pérez,* Víctor Manuel Martínez-Aguilar,* Elda Georgina Chávez-Cortéz ${ }^{\ddagger}$ \\ * Facultad de Odontología de la Universidad Autónoma de Yucatán. Mérida, Yucatán; ${ }^{\ddagger}$ Facultad de \\ Odontología de la Universidad Autónoma de Baja California. Mexicali, Baja California.
}

\section{RESUMEN}

La hiperplasia epitelial multifocal (HEM) es una lesión benigna y asintomática, asociada al virus del papiloma humano (VPH). Se caracteriza por pápulas de apariencia verrugosa, localizadas en labios, lengua, carrillos, paladar y encía. Objetivo: Describir el caso de una niña con HEM en quien se utilizó ácido tricloroacético (TCA) para su tratamiento. Presentación del caso: Paciente de ocho años que presenta lesiones en lengua y carrillos, de tipo pápulo-nodulares. El diagnóstico de HEM se confirmó mediante detección de VPH. En 15 sesiones se realizaron aplicaciones semanales de TCA al $90 \%$ en los sitios afectados, apreciándose cambios positivos a partir de los ocho días. A 10 meses de seguimiento, se observó la disminución del volumen de las lesiones y de la sintomatología. Conclusión: El TCA al 90\% parece ser una opción efectiva para el tratamiento de HEM en niños.

Palabras clave: Hiperplasia epitelial multifocal, virus de papiloma humano, ácido tricloroacético, mucosa bucal, lengua, niños.

\section{INTRODUCCIÓN}

La hiperplasia epitelial multifocal (HEM), o enfermedad de Heck, suele manifestarse entre los tres y 18 años de edad, ${ }^{1,2}$ con un ligero predominio por el sexo femenino. ${ }^{3}$ Es una enfermedad que afecta la mucosa

\begin{abstract}
Multifocal epithelial hyperplasia (MEH) is a benign lesion associated with the human papillomavirus. It is characterized by warty-looking papules located on the lips, tongue, cheeks, palate, and gums. Objective: To describe the case of a girl with MEH in whom trichloroacetic acid (TCA) was used for her treatment. Case report: Eight-year-old patient with papulonodular lesions on the tongue and cheeks. The diagnosis of MEH was confirmed by detection of HPV. Weekly applications of TCA at $90 \%$ were performed on the affected sites, for 15 sessions. Positive changes were seen after eight days. At 10 months of follow-up, a decrease in the volume of the lesions and in the symptoms was observed. Conclusion: TCA seems to be an effective option for the treatment of MEH in children.
\end{abstract}

Keywords: Multifocal epithelial hyperplasia, human papillomavirus, trichloroacetic acid, tongue, buccal mucosa, tongue, children.

Correspondencia: Martha Gabriela Chuc-Gamboa, E-mail: martha.chuc@correo.uady.mx

Citar como: Muñoz-Trejo CA, Rosado-Rosado DV, Chuc-Gamboa MG, Aguilar-Pérez FJ, Martínez-Aguilar VM, Chávez-Cortéz EG. Ácido tricloroacético como tratamiento para hiperplasia epitelial multifocal. Rev Mex Pediatr. 2021; 88(5): 192-195. https://dx.doi.org/10.35366/103899

de los labios, mucosa yugal, lengua, carrillos, paladar y encías. ${ }^{4-7}$

Se manifiesta mediante lesiones benignas asintomáticas asociadas al virus del papiloma humano (VPH) 13 y $32,{ }^{3}$ con pápulas múltiples, de aproximadamente 3 a $10 \mathrm{~mm}$, del color del tejido circundante, 
con base sésil, consistencia blanda y de superficie lisa o rugosa. ${ }^{3,8}$

Para el diagnóstico, primero se debe realizar un examen físico minucioso, ${ }^{7,9}$ además de realizar análisis por patología mediante microscopía electrónica, así como reacción en cadena de la polimerasa $(\mathrm{PCR})$ para determinar los subtipos de virus., ${ }^{2,9-11}$

El tratamiento solamente está indicado cuando existen traumas que interfieran en la función masticatoria o por estética, ya que estas lesiones pueden persistir meses, años, e incluso no involucionar. ${ }^{7,12}$

Las opciones de tratamiento para la HEM son variables y abarcan desde la eliminación de las lesiones por cirugía escisional convencional, láser de $\mathrm{CO}_{2}$, electrocoagulador o la criocirugía. Sin embargo, otras formas terapéuticas tópicas y menos invasivas incluyen la aplicación de Imiquimod crema al 5\%, ácido retinoico, interferón beta, resina de podofilino, agentes inmunomodulares y ácido tricloroacético (TCA). 1,3,12

El TCA es un agente cáustico que se deriva del ácido acético. Cuando la aplicación es tópica, presenta un efecto queratolítico y cauterizante, dando como resultado la desnaturalización, precipitación y destrucción de las lesiones a través de la coagulación química, con lo que se espera disminución de las lesiones. ${ }^{12}$ La naturaleza destructiva del compuesto a menudo se extiende más allá de la lesión superficial, lo que permite la eliminación viral de 70-80\%. El compuesto tiene bajo riesgo de absorción sistémica, por lo que su aplicación es segura. La profundidad de la necrosis está relacionada con la concentración de TCA, por lo cual las concentraciones terapéuticas varían de 80-90\%. El tratamiento puede ocasionar una sensación de ardor leve, pero es transitorio. ${ }^{5}$

A pesar de que la HEM es una patología ampliamente estudiada, la información acerca de la terapéutica es limitada. Por tal motivo, el propósito del presente caso es dar a conocer el resultado del tratamiento con TCA en un paciente pediátrico.

\section{PRESENTACIÓN DEL CASO}

Paciente femenino de ocho años que acude a la Facultad de Odontología de la Universidad Autónoma de Yucatán manifestando molestias en la lengua durante la masticación. Refiere un año de evolución de lesiones en la boca, con crecimiento progresivo. Al interrogatorio se encuentran antecedentes de lesiones similares en la familia por parte de la madre y tías.

Clínicamente se aprecian lesiones de configuración pápulo-nodulares de color rosado, blandas, de base sésil, coalescentes, con bordes definidos y textura lisa, localiza- das en las caras laterales y dorsal de la lengua, carrillos y labio inferior, por lo que se sospechó de HEM (Figura 1).

Previo consentimiento informado, se realizó PCR de una muestra de saliva. La identificación positva del VPH subtipo 13 se realizó en el Centro de Investigación Regional «Dr. Hideyo Noguchi», de acuerdo al protocolo reportado por Carrillo y colaboradores. ${ }^{13}$

El plan de tratamiento consistió en la aplicación local de una solución acuosa de TCA al 90\% (volumen/ volumen), una vez por semana, durante 10 semanas. Durante cada sesión se realizó un protocolo de aislamiento relativo con algodón y gasas para la protección de labios, carrillos y tejidos peribucales. A continuación, se secó la zona afectada empleando la salida de aire de la jeringa triple de la unidad dental. Posteriormente, mediante hisopos embebidos de TCA, se procedió a la aplicación de manera tópica, únicamente en las lesiones de la lengua, adquiriendo una tonalidad blanquecina al contacto con la solución, la cual se dejó actuar durante 60 segundos.
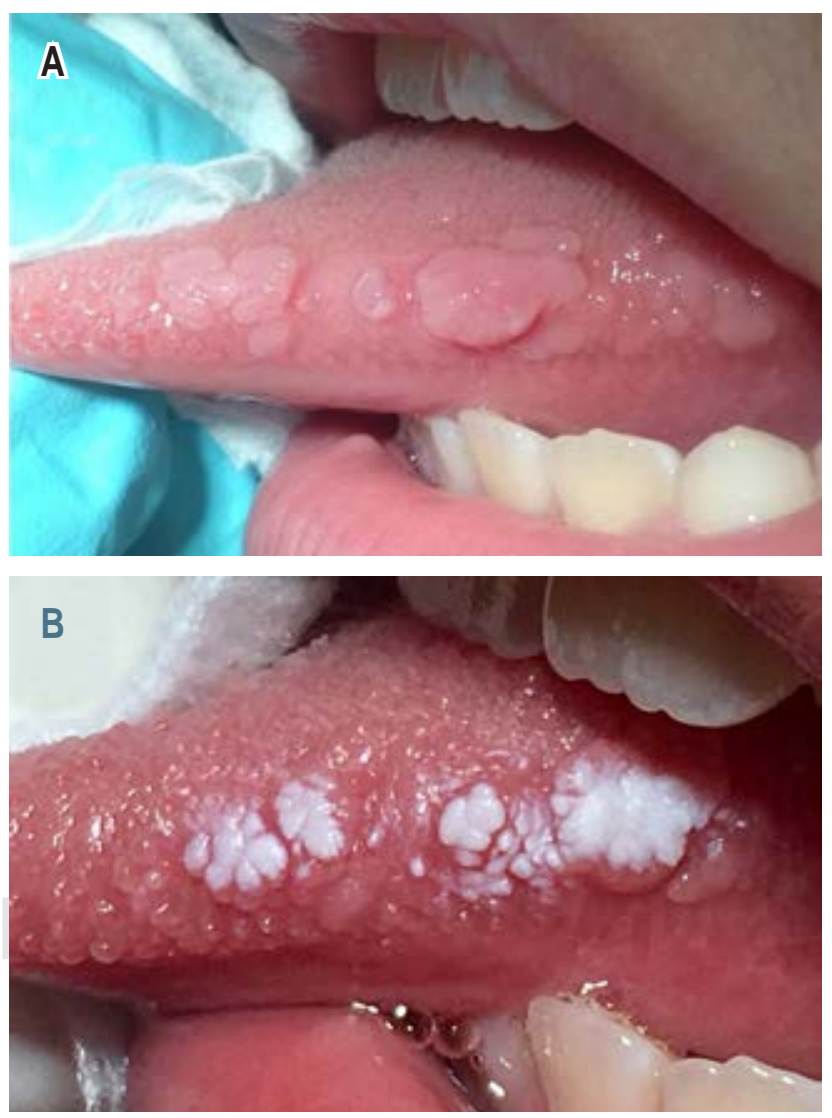

Figura 1: Imágenes de las lesiones en lengua. A) Inicial. B) Posterior a la primera aplicación del tratamiento. 

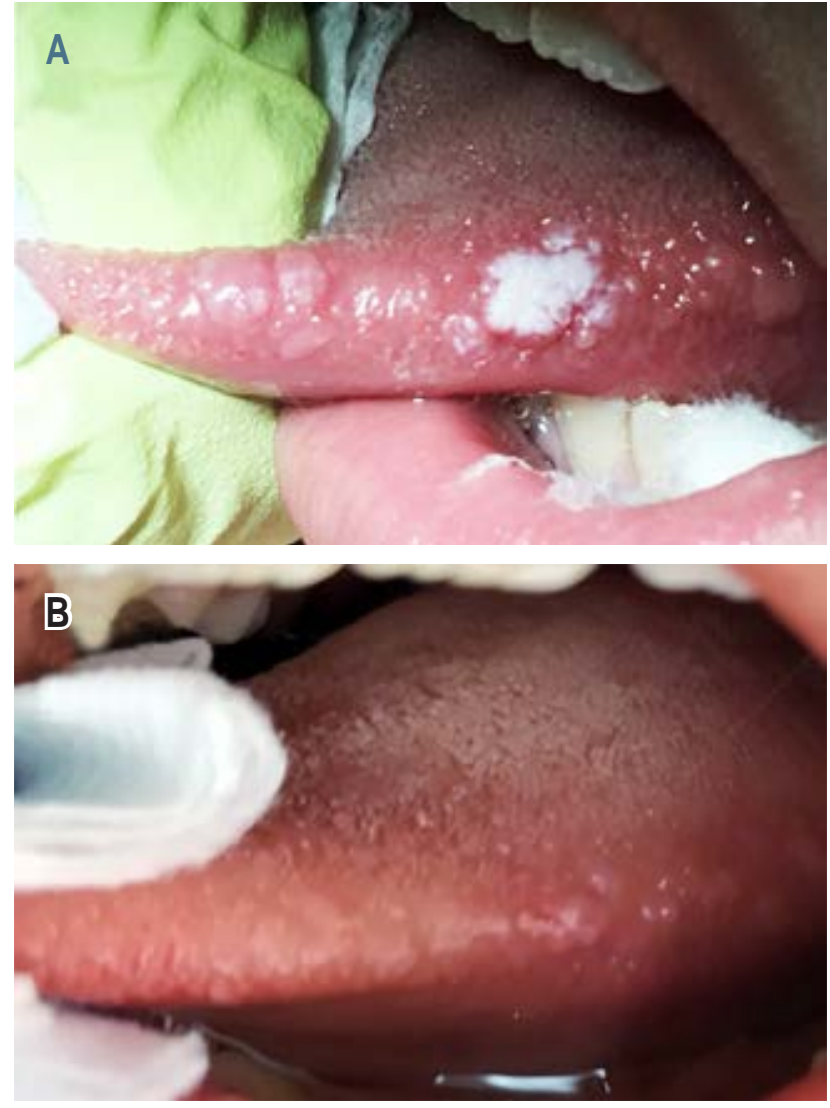

Figura 2: Imágenes de las lesiones en lengua. A) Posterior a la aplicación en la semana 10. B) Seguimiento a los 10 meses.

Al finalizar el tratamiento, se observó que las pápulas disminuyeron, pero sin llegar a resolución completa (Figura 2). Se dieron citas de seguimiento mensuales en las que se preguntaba sobre sintomatología, y se analizaba el tamaño de las lesiones. Después de seis meses, a pesar de cierta disminución de los síntomas, se decidió realizar cinco aplicaciones más (una por semana), con el propósito de lograr una mejor resolución. Al término, hubo disminución del volumen de las lesiones, con una apariencia más aplanada (Figura 2). La paciente también manifestó mejoría en la sintomatología, refiriendo que no había interferencia en la función masticatoria.

\section{DISCUSIÓN}

La HEM es una entidad descrita inicialmente en nativos americanos; sin embargo, afecta a diferentes poblaciones. ${ }^{2}$ Agnew y colaboradores reportan que la ocurrencia entre familias y la predilección étnica de esta patología, podría estar relacionado a predisposición genética. ${ }^{10} \mathrm{En}$ el caso presentado se informó que familiares directos de la paciente también padecieron dicha enfermedad.

Dado que puede existir involución, el tratamiento para la HEM se circunscribe a pacientes con lesiones que afectan la función del habla (son estéticamente desagradables), o bien, cuando interfieren con la masticación o generan dolor. ${ }^{14}$ Nuestra paciente refería molestias durante la masticación debido al trauma generado en las lesiones por la oclusión, por lo que se decidió ofrecer tratamiento.

En los últimos años se han empleado diversas alternativas de tratamiento. Patil y su equipo ${ }^{15}$ reportan como primera opción la escisión quirúrgica; sin embargo, en el presente caso, se decidió el tratamiento con TCA por la edad de la paciente. El TCA se utiliza para tratamiento de verrugas genitales y perianales, ${ }^{12}$ pero los reportes en la literatura acerca de la aplicación de TCA en la cavidad oral son escasos.

Harris y colegas, en 2016, evaluaron la efectividad de la terapia con TCA al 80\%, reportando eliminación completa de las lesiones en un tiempo promedio de 61 días. $^{5}$ En este estudio obtuvimos un resultado diferente, es decir, no hubo resolución completa de las lesiones, a pesar de utilizar una mayor concentración de TCA (90\%). No obstante, dado que se obtuvo disminución significativa del volumen y desaparición del trauma, consideramos que el tratamiento fue exitoso.

Delgado reporta que uno de los tratamientos atraumáticos para tumoraciones pequeñas o escasas es la solución de TCA al 35-80\% en toques, hasta obtener un blanqueamiento coagulante de las lesiones por precipitación proteica y desvitalización tisular; ${ }^{16}$ además, sugiere que las aplicaciones deben ser efectuadas a intervalos quincenales o mensuales, hasta cuatro o cinco sesiones.

\section{CONCLUSIÓN}

Nuestros resultados demuestran que el tratamiento con TCA para HEM podría ser considerado como una alternativa terapéutica en niños.

\section{AGRADECIMIENTOS}

Al Centro de Investigación Regional «Dr. Hideyo Noguchi», por la realización de la prueba de PCR para la detección del virus. 


\section{REFERENCIAS}

1. Bertolotti ML, Abbiati A, Verea MA, Pecotche DM. Hiperplasia epitelial focal o enfermedad de Heck. Presentación de un caso. Medisur. 2016; 14(6): 767-771.

2. González-Losa M, Suarez-Allén R, Canul-Canche J, CondeFerráez L, Eljure-Lopez M. Multifocal epithelial hyperplasia in a community in the Mayan area of Mexico. Int J Dermatol. 2011; 50(3): 304-309.

3. Gonzalez-Losa MR, Barrera ES, Herrera-Pech V, Conde-Ferráez L, Puerto-Solís M, Ayora-Talavera G. Epidemiology of oral HPV in the oral mucosa in women without signs of oral disease from Yucatan, Mexico. Braz J Microbiol. 2015; 46(1): 301-306.

4. Martínez-Serna IV, Hernández-Molinar Y, Tejeda-Nava FJ, Bologna-Molina R, Aranda-Romo S. Hiperplasia epitelial multifocal: reporte de tres casos clínicos y revisión de la literatura. Rev ADM. 2014; 71(1): 23-27.

5. Harris-Ricardo J, Carmona-Lorduy M, Díaz-Caballero A. Efectividad de la terapia con ácido tricloroacético en el tratamiento de lesiones en la hiperplasia epitelial focal. Rev Odont Mex. 2016; 20(4): 243-247.

6. Ghalayani P, Tavakoli P, Eftekhari M, Haghighi MA. Oral focal epithelial hyperplasia: report of three cases. Turk Patoloji Derg. 2015; 31(1): 60-63.

7. Lopez-Villanueva ME, Conde-Ferráez L, Ayora-Talavera G, CerónEspinosa JD, González-Losa Mdel R. Human papillomavirus 13 in a Mexican Mayan community with multifocal epithelial hyperplasia: could saliva be involved in household transmission? Eur J Dermatol. 2011; 21(3): 396-400.

8. Mahmoudi H, Balighi K, Tavakolpour S, Daneshpazhooh M, Chams-Davatchi C. Trichloroacetic acid as a treatment for persistent oral mucosal lesions in pemphigus vulgaris. J Am Acad Dermatol. 2019; 80(3): e51-e52.

9. Nallanchakrava S, Sreebala N, Basavaraj, Sindgi F. Laser excision of focal epithelial hyperplasia (Heck's disease): a rare case report. Int J Clin Pediatr Dent. 2018; 11(6): 526-528.

10. Agnew $C$, Alexander S, Prabhu N. Multifocal epithelial hyperplasia. $J$ Dent Child (Chic). 2017; 84(1): 47-49.

11. Navarro-Vidal E, Hernandez-Rosas F, Rey M, Flores-Peredo L. Prevalence of human papillomavirus genotypes in women from Cozumel, Mexico. Asian Pac J Cancer Prev. 2018; 19(9): 24172422.

12. Tovío-Martínez E, Espítatela-Mejía M, Carbonell-Muñoz Z, Luz-Luna R, Harris-Ricardo J. Evaluation of clinical results from trichloroacetic acid on the treatment of focal epithelial hyperplasia. OHDM. 2018; 17(1): 1-4.

13. Carrillo JE, Conde L, Ayora G, Puerto M, González MR. Estudio de la hiperplasia epitelial multifocal en tres comunidades rurales del Estado de Yucatán, México. Rev Biomed. 2015; 26(3): 133-137.

14. Paz-Betanco MA. Hiperplasia epitelial multifocal en un niño de una comunidad rural de Chinandega, Nicaragua. Reporte de caso. Rev Venez Invest Odont IADR. 2018; 6(2): 233-243.

15. Patil K, Guledgud MV, Sanjay CJ, Penumatsa B. Oral multifocal epithelial hyperplasia: an unusual entity. Int J Appl Basic Med Res. 2019; 9(4): 253-255.

16. Delgado EJ. Hiperplasia epitelial focal. Dermatol Peru. 2018; 28(4): 220-224.

\section{Conflicto de intereses: Los autores declaran que} no tienen. 